\title{
ANALISIS WORK ATTITUDE DAN JOB PERFORMANCE PROGRAM POKOK PUSKESMAS DI KABUPATEN GRESIK
}

\author{
Anif Prasetyorini \\ STIKES Yayasana Rumah Sakit Dr. Soetomo, Jl. Karangmenjangan 12 Surabaya 60286 \\ Surel : prodisars@yahoo.com
}

\begin{abstract}
ABSTRAK
Penelitian ini bertujuan menyusun strategi peningkatan cakupan program pokok Puskesmas berdasarkan analisis efektivitas tim, work attitude dan job performance unit kerja Puskesmas di Kabupaten Gresik. Jenis Penelitian adalah penilitian analitik dengan metode observasional yang bersifat cross sectional study dengan populasi seluruh unit kerja program pokok Puskesmas di Kabupaten Gresik. Hasil penelitian menunjukkan bahwa work attitude unit kerja termasuk dalam kategori cukup dengan penilaian terendah pada subvariabel organizational commitment. Job performance unit kerja termasuk dalam kategori cukup dengan penilaian terendah pada OCB khususnya dimensi conscientiousness. Cakupan program pokok Pukskesmas di Kabupaten Gresik termasuk dalam kategori baik. Peningkatan cakupan program pokok Puskesmas dapat dilakukan dengan cara meningkatkan job satisfaction, job involvement, organizational commitment dan in role performance unit kerja Puskesmas.
\end{abstract}

\section{Kata Kunci : work attitude, job performance, cakupan program pokok}

\section{ABSTRACT}

The purpose of this research was to develop a strategy to improve the main program coverage of Community Health Center based on work attitude, and job performance of Community Health Center in Gresik District. This was an analytic observational research with cross-sectional design. The results showed that work attitude of work units included in the category of moderate with sub variable organizational commitment as the lowest-rated. Job performance of work units included in the category of moderate with OCB especially conscientiousness as the lowest-rated. The improvement of main program coverage can be done by increasing job satisfaction, job involvement, organization commitment and in role performance.

Puskesmas adalah unit pelaksana teknis dinas kesehatan kabupaten atau kota yang bertanggungjawab menyelenggarakan pembangunan kesehatan di suatu wilayah kerja tertentu. Puskesmas berfungsi sebagai (1) Pusat penggerak pembangunan berwawasan kesehatan; (2) Pusat pemberdayaan keluarga dan masyarakat (3) Pusat pelayanan kesehatan masyarakat primer (4) Pusat pelayanan kesehatan perorangan primer (Dinkes Jatim, 2011).

Menurut Kepmenkes no 128 tahun 2004, untuk menjalankan fungsi Puskesmas ada dua upaya yang dilakukan oleh Puskesmas yaitu Pelayanan Pokok dan Pelayanan Pengembangan. 
Tabel 1.2 Cakupan Program Pokok Puskesmas Berdasarkan Kategori Kinerja di Kabupaten Gresik Tahun 2010 dan Tahun 2011

\begin{tabular}{|l|c|c|c|c|}
\hline \multirow{2}{*}{ Kategori } & \multicolumn{4}{|c|}{ Cakupan Program Pokok Puskesmas } \\
\cline { 2 - 5 } & \multicolumn{3}{|c|}{ Tahun 2010} & \multicolumn{2}{c|}{ Tahun 2011 } \\
\cline { 2 - 5 } & $\mathrm{n}$ & $\%$ & $\mathrm{n}$ & $\%$ \\
\hline Baik & 27 & 84,38 & 7 & 21,87 \\
\hline Cukup & 3 & 9,37 & 21 & 65,63 \\
\hline Kurang & 2 & 6,25 & 4 & 12,5 \\
\hline Total & 32 & 100 & 32 & 100 \\
\hline
\end{tabular}

Sumber : Data Sekunder Penilaian Kinerja Puskesmas Dinas Kesehatan Kabupaten Gresik Tahun $2010 \& 2011$

Pada Tabel 1.2 menunjukkan bahwa ada penurunan jumlah Puskesmas yang memiliki cakupan program pokok dengan kategori baik sebesar $62,51 \%$ di Kabupaten Gresik pada tahun 2010 s/d tahun 2011.

Menurut McCook (2002), job performance (in role performance dan extra role performance) dipengaruhi oleh work attitude (job satisfaction, job involvement dan organizational commitment). Adanya peran extra role performance melalui Organizational Citizenship Behaviour (OCB) petugas pemegang program pokok masing-masing Puskesmas diharapkan dapat meningkatkan cakupan program pokok Puskesmas.

Tujuan penelitian ini adalah untuk menyusun strategi peningkatan cakupan program pokok Puskesmas berdasarkan analisis work attitude dan job performance unit kerja Puskesmas di Kabupaten Gresik.

\section{METODE}

Jenis Penelitian ini adalah penilitian analitik dengan metode observasional. Berdasarkan waktu penelitian, penelitian ini bersifat cross sectional study. Lokasi penelitian ini di Puskesmas Kabupaten Gresik, sedangkan pelaksanaan penelitian ini akan dilaksanakan pada bulan Januari s/d Juni 2013. Populasi pada penelitian ini adalah seluruh unit kerja program pokok Puskesmas di Kabupaten Gresik. Sampel penelitian ini adalah unit kerja program pokok Puskesmas di Puskesmas terpilih. Sedangkan unit analisis pada penelitian ini adalah unit kerja program pokok Puskesmas dengan kriteria inklusi yaitu unit kerja yang dikerjakan secara tim, bukan secara individu. Besar sampel dalam penelitian ini adalah 90 unit kerja dalam 15

Koordinator program pokok Puskesmas pada masing-masing unit kerja adalah sumber informasi untuk mengetahui variabel efektivitas tim, work attitude dan job performance unit kerja Puskesmas di Kabupaten Gresik adalah. Sedangkan sumber informasi untuk mengukur variabel cakupan program pokok Puskesmas adalah hasil penilaian kinerja Puskesmas pada tahun 2012.

Puskesmas yang diambil secara proporsional menurut strata kategori kinerja Puskesmas dan kategori letak geografis Puskesmas. Teknik pengambilan sampel dalam penelitian ini menggunakan teknik stratified random sampling. Kuesioner dilakukan uji pearson correlation untuk melihat validitas dan reliability analisis dengan memperhatikan nilai cronbach alpha untuk melihat reliabilitas. Data dikumpulkan dari responden melalui wawancara dengan panduan kuesioner, check list sebagai media observasi terhadap dokumen serta dilakukan Focus Group Discussion (FGD).

Adapun kerangka operasional dalam penelitian ini adalah, pada tahap pertama peneliti mengidentifikasi efektivitas tim (misi tim, pencapaian tujuan, pemberdayaan, komunikasi yang jujur dan terbuka, peran dan norma yang positif), work attitude (job satisfaction, organizational commitment dan job involvement) unit kerja Puskesmas, job 
performance (in role performance dan organizational citizenship behaviour) dan cakupan program pokok Puskesmas di Kabupaten Gresik.

Tahap kedua, menganalisis pengaruh job satisfaction terhadap organizational commitment unit kerja Puskesmas, kemudian menganalisis pengaruh job satisfaction dan organizational commitment terhadap job involvement unit kerja Puskesmas. Menganalisis pengaruh work attitude (job satisfaction, organizational commitment dan job involvement) terhadap efektivitas tim unit kerja Puskesmas. Menganalisis pengaruh efektivitas tim dan work attitude terhadap job performance. Menganalisis pengaruh efektivitas tim, job satisfaction, job involvement dan organizational commitment terhadap job performance. Menganalisis pengaruh efektivitas tim, job satisfaction, organizational commitment dan job involvement terhadap in role performance. Kemudian menganalisis pengaruh efektivitas tim, job satisfaction, organizational commitment dan job involvement terhadap organizational citizenship behaviour unit kerja Puskesmas di Kabupaten Gresik.

Tahap ketiga, menganalisis pengaruh efektivitas tim, wok attitude dan Tabel 3.2 Hasil Identifikasi Work Attitude Unit Kerja Puskesmas di Kabupaten Gresik Tahun 2013

\begin{tabular}{|c|c|c|c|c|c|c|c|}
\hline \multirow[t]{3}{*}{ No } & \multirow[t]{3}{*}{ Unit kerja } & \multicolumn{6}{|c|}{ Kategori Work Attitude } \\
\hline & & \multicolumn{2}{|c|}{ Kurang } & \multicolumn{2}{|c|}{ Cukup } & \multicolumn{2}{|c|}{ Baik } \\
\hline & & $\mathrm{n}$ & $\%$ & $\mathrm{n}$ & $\%$ & $\mathrm{n}$ & $\%$ \\
\hline 1 & Promkes & 3 & 20 & 9 & 60 & 3 & 20 \\
\hline 2 & Kesling & 4 & 26,7 & 10 & 66,7 & 1 & 6,7 \\
\hline 3 & KB & 0 & 0 & 10 & 66,7 & 5 & 33,3 \\
\hline 4 & KIA & 3 & 20 & 10 & 66,7 & 2 & 13,3 \\
\hline 5 & Gizi & 1 & 6,7 & 12 & 80 & 2 & 13,3 \\
\hline 6 & Pengobatan & 3 & 20 & 9 & 60 & 3 & 20 \\
\hline \multicolumn{2}{|c|}{ Jumlah } & 14 & 15,6 & 60 & 66,7 & 16 & $\mathbf{1 7 , 8}$ \\
\hline
\end{tabular}

Sumber : Data primer

Menurut tabel 3.2 dapat diketahui bahwa rata-rata kategori work attitude unit kerja Puskesmas di Kabupaten Gresik adalah cukup. Hasil work attitude tertinggi terletak pada unit kerja $\mathrm{KB}$, sedangkan work attitude terendah terletak pada unit job performance unit kerja Puskesmas terhadap cakupan program pokok Puskesmas di Kabupaten Gresik. Kemudian menganalisis pengaruh efektivitas tim, job satisfaction, organizational commitment, job involvement, in role performance dan organizational citizenship behaviour unit kerja Puskesmas terhadap cakupan program pokok Puskesmas.

Tahap keempat, hasil analisis akan didapatkan isu strategis. Isu strategis selanjutnya ditelaah oleh peneliti dan dilakukan diskusi kelompok dengan menggunakan FGD dan hasil dari FGD dapat digunakan sebagai masukan peneliti dalam pembahasan penelitian. Menyusun strategi peningkatan cakupan program pokok Puskesmas berdasarkan analisis efektivitas tim, work attitude dan job performance unit kerja Puskesmas di Kabupaten Gresik. Kemudian analisis statistik yang digunakan adalah Regresi Linier.

\section{HASIL DAN PEMBAHASAN}

Sikap kerja berisi evaluasi positif atau negative yang dimiliki oleh karyawan tentang aspek dalam lingkungan kerja. Hasil identifikasi work attitude unit kerja Puskesmas dapat dilihat pada tabel 3.2. 
Hasil identifikasi job satisfaction

Tahun 2013 dapat dilihat pada tabel 3.3.

unit kerja Puskesmas di Kabupaten Gresik

Tabel 3.3 Hasil Identifikasi Job Satisfaction Unit Kerja Puskesmas di Kabupaten Gresik

Tahun 2013

\begin{tabular}{|c|l|c|c|c|c|c|c|}
\hline \multirow{2}{*}{ No } & \multirow{2}{*}{ Unit kerja } & \multicolumn{6}{c|}{ Kategori Job Satisfaction } \\
\cline { 3 - 8 } & & \multicolumn{2}{|c|}{ Kurang } & \multicolumn{2}{c|}{ Cukup } & \multicolumn{2}{c|}{ Baik } \\
\cline { 3 - 8 } & & $\mathrm{n}$ & $\%$ & $\mathrm{n}$ & $\%$ & $\mathrm{n}$ & $\%$ \\
\hline 1 & Promkes & 2 & 13,3 & 8 & 53,3 & 5 & 33,3 \\
\hline 2 & Kesling & 4 & 26,7 & 9 & 60 & 2 & 13,3 \\
\hline 3 & KB & 1 & 6,7 & 8 & 53,3 & 6 & 40 \\
\hline 4 & KIA & 3 & 20 & 10 & 66,7 & 2 & 13,3 \\
\hline 5 & Gizi & 1 & 6,7 & 12 & 80 & 2 & 13,3 \\
\hline 6 & Pengobatan & 4 & 26,7 & 6 & 40 & 5 & 33,3 \\
\hline \multicolumn{2}{r}{ Jumlah } & $\mathbf{1 7}$ & $\mathbf{1 8 , 9}$ & $\mathbf{5 4}$ & $\mathbf{6 0}$ & $\mathbf{1 9}$ & $\mathbf{2 1 , 1}$ \\
\hline
\end{tabular}

Sumber : Data primer

Tingkat kepuasan kerja unit kerja

Puskesmas terbanyak adalah cukup.

Kepuasan kerja tertinggi terletak pada unit kerja KB, sedangkan kepuasan kerja terendah terletak pada unit kerja kesehatan lingkungan.

Komitmen organisasi (organizational commitment) sebagai suatu

keadaan di mana seorang karyawan memihak organisasi tertentu serta tujuan dan keinginannya untuk mempertahankan keanggotaan dalam organisasi tersebut. Hasil identifikasi organizational commitment unit kerja Puskesmas di Kabupaten Gresik tahun 2013 dapat dilihat pada tabel 3.4.

Tabel 3.4 Hasil Identifikasi Organizational Commitment Unit Kerja Puskesmas di Kabupaten Gresik Tahun 2013

\begin{tabular}{|c|c|c|c|c|c|c|c|c|c|}
\hline \multirow[t]{3}{*}{ No } & \multirow[t]{3}{*}{ Unit Kerja } & \multicolumn{8}{|c|}{ Kategori Organizational Commitment } \\
\hline & & \multicolumn{2}{|c|}{ Sangat Kurang } & \multicolumn{2}{|c|}{ Kurang } & \multicolumn{2}{|c|}{ Cukup } & \multicolumn{2}{|c|}{ Baik } \\
\hline & & $\mathrm{n}$ & $\%$ & $\mathrm{n}$ & $\%$ & $\mathrm{n}$ & $\%$ & $\mathrm{n}$ & $\%$ \\
\hline 1 & Promkes & 2 & 13,3 & 8 & 53,3 & 1 & 6,7 & 4 & 26,7 \\
\hline 2 & Kesling & 3 & 20 & 3 & 20 & 5 & 33,3 & 4 & 26,7 \\
\hline 3 & KB & 0 & 0 & 1 & 6,7 & 2 & 13,3 & 12 & 80 \\
\hline 4 & KIA & 1 & 6,7 & 4 & 26,7 & 2 & 13,3 & 8 & 53,3 \\
\hline 5 & Gizi & 1 & 6,7 & 1 & 6,7 & 7 & 46,7 & 6 & 40 \\
\hline 6 & Pengobatan & 1 & 6,7 & 7 & 46,7 & 2 & 13,3 & 5 & 33,3 \\
\hline & Jumlah & 8 & 8,9 & 24 & 26,7 & 19 & 21,1 & 39 & 43,3 \\
\hline
\end{tabular}

Sumber : Data primer

Menurut tabel 3.4 dapat dilihat bahwa sebagian besar komitmen tim unit kerja Puskesmas adalah baik. Komitmen tim tertinggi terletak pada unit kerja KB, sedangkan komitmen tim terendah terletak pada unit kerja promosi kesehatan.

Keterlibatan pekerjaan menunjukkan tingkat sampai mana individu secara psikologis memihak pekerjaannya dan menganggap penting tingkat kinerja yang dicapai sebagai bentuk penghargaan diri.
Hasil identifikasi job involvement unit kerja Puskesmas dapat dilihat pada tabel 3.5 
Tabel 3.5 Hasil Identifikasi Job Involvement Unit Kerja Puskesmas di Kabupaten Gresik Tahun 2013

\begin{tabular}{|c|c|c|c|c|c|c|c|c|c|}
\hline \multirow[t]{3}{*}{ No } & \multirow[t]{3}{*}{ Unit Kerja } & \multicolumn{8}{|c|}{ Kategori Job Involvement } \\
\hline & & \multicolumn{2}{|c|}{ Sangat Kurang } & \multicolumn{2}{|c|}{ Kurang } & \multicolumn{2}{|c|}{ Cukup } & \multicolumn{2}{|c|}{ Baik } \\
\hline & & $\mathrm{n}$ & $\%$ & $\mathrm{n}$ & $\%$ & $\mathrm{n}$ & $\%$ & $\mathrm{n}$ & $\%$ \\
\hline 1 & Promkes & 0 & 0 & 5 & 33,3 & 9 & 60 & 1 & 6,7 \\
\hline 2 & Kesling & 1 & 6,7 & 3 & 20 & 10 & 66,6 & 1 & 6,7 \\
\hline 3 & KB & 0 & 0 & 2 & 13,3 & 8 & 53,3 & 5 & 33,3 \\
\hline 4 & KIA & 0 & 0 & 4 & 26,7 & 8 & 53,3 & 3 & 20 \\
\hline 5 & Gizi & 0 & 0 & 2 & 13,3 & 10 & 66,7 & 3 & 20 \\
\hline 6 & Pengobatan & 0 & 0 & 5 & 33,3 & 6 & 40 & 4 & 26,7 \\
\hline & Jumlah & 1 & 1,1 & 21 & 23,3 & 51 & 56,7 & 17 & 18,9 \\
\hline
\end{tabular}

Sumber : Data primer

Tabel 3.5 menunjukkan bahwa sebagian besar kategori keterlibatan kerja unit kerja Puskesmas di Kabupaten Gresik adalah cukup. Job involvement terbaik terletak pada unit kerja KB, sedangkan job involvement terendah terletak pada unit kerja kesehatan lingkungan.

Sebagian besar kategori work attitude unit kerja puskesmas di Kabupaten Gresik adalah cukup. Work attitude yang memiliki penilaian terendah adalah organizational commitment. Berdasarkan analisis statistik organizational commitment dapat mempengaruhi organizational citizenship behaviour unit kerja puskesmas. Menurut Pantja Djati (2011) meningkatnya perilaku OCB dipengaruhi oleh dua faktor utama, yaitu faktor yang berasal dari dalam diri karyawan (internal) dan faktor yang berasal dari luar karyawan (eksternal). Komitmen karyawan merupakan salah satu faktor internal yang dapat mempengaruhi perilaku OCB.

Unit kerja promosi kesehatan memiliki penilaian terendah pada organizational commitment. Robbins dan Judge (2008), mendefinisikan komitmen organisasi (organizational commitment) sebagai suatu keadaan di mana seorang karyawan memihak organisasi tertentu serta tujuan dan keinginannya untuk mempertahankan keanggotaan dalam organisasi tersebut. Akan tetapi jika ada anggota unit kerja yang tidak dapat

memihak organisasinya maka tingkat komitmen orang tersebut termasuk kurang. Unit kerja kesehatan lingkungan memiliki work attitude yang paling rendah di antara unit kerja yang lain. Work attitude kesehatan lingkungan memiliki penilaian terendah pada variable job involvement dan job satisfaction. Dimensi tentang job satisfaction yang disampaikan oleh Emilisa (2001) bahwa financial reward dan promotion opportunities merupakan variabel yang secara nyata berhubungan dengan kepuasan kerja.

$\mathrm{KB}$ memiliki work attitude terendah pada job involvement. Adapun penyebab rendahnya job involvement pada unit kerja $\mathrm{KB}$ adalah kurangnya komunikasi yang baik antar unit kerja maupun antar petugas yang ada di dalam unit kerja serta pimpinan Puskesmas, kurangnya kemampuan dan ketrampilan yang dimiliki oleh anggota unit kerja, adanya rasa jenuh terhadap pekerjaan dan insentif yang diperoleh.

Keterlibatan kerja dapat dipengaruhi oleh dua variabel, yaitu variabel personal dan variabel situasional. Variabel personal yang dapat mempengaruhi keterlibatan kerja meliputi variabel demografi dan psikologis. Variabel demografi mencakup usia, pendidikan, jenis kelamin, status pernikahan, jabatan, dan senioritas. Variabel situasional yang dapat mempengaruhi keterlibatan kerja mencakup pekerjaan, organisasi, dan lingkungan sosial budaya. Variabel 
pekerjaan mencakup karakteristik/hasil kerja, variasi, otonomi, identitas tugas, feedback, level pekerjaan (status formal dalam organisasi), level gaji, kondisi pekerjaan (work condition), job security, supervisi, dan iklim interpersonal.

KIA, gizi dan pengobatan memiliki work attitude terendah pada variabel organizational commitment. Penyebab rendahnya organizational commitment terletak pada kurangnya kepuasan pada pekerjaan yang dipegang. Robbins (1996) mengungkapkan dampak kepuasan kerja jika dipenuhi dapat meningkatkan produktifitas, menurunkan abesentisme, menekan perputaran kerja. Job satisfaction mempunyai peran dalam peningkatan organizational commitment unit kerja pengobatan.
Rendahnya komitmen organisasi pada unit kerja pengobatan terletak pada kepuasan terhadap pekerjaan itu sendiri, yaitu kurangnya rasa motivasi akibat tidak adanya perkembangan kemampuan yang dimiliki oleh tenaga kerja. Menurut Depkes RI (2009) menyebutkan bahwa fungsi puskesmas tentang pemberian pelayanan kesehatan termasuk pada fungsi yang ketiga bukan yang utama. Sehingga penerapan ilmu pengobatan hanya terbatas pada jenis pemberian pelayanan pada tahap strata.

Job performance dalam dua domain yaitu task performance dan contextual performance. Hasil identifikasi job performance unit kerja Puskesmas di Kabupaten Gresik tahun 2013 dapat dilihat pada tabel 3.6.

Tabel 3.6 Hasil Identifikasi Job Performance Unit Kerja Puskesmas di Kabupaten Gresik Tahun 2013

\begin{tabular}{|c|c|c|c|c|c|c|c|c|c|}
\hline \multirow[t]{3}{*}{ No } & \multirow[t]{3}{*}{ Unit Kerja } & \multicolumn{8}{|c|}{ Kategori Job Performance } \\
\hline & & \multicolumn{2}{|c|}{$\begin{array}{l}\text { Sangat } \\
\text { Kurang }\end{array}$} & \multicolumn{2}{|c|}{ Kurang } & \multicolumn{2}{|c|}{ Cukup } & \multicolumn{2}{|c|}{ Baik } \\
\hline & & $\mathrm{n}$ & $\%$ & $\mathrm{n}$ & $\%$ & $\mathrm{n}$ & $\%$ & $\mathrm{n}$ & $\%$ \\
\hline 1 & Promkes & 0 & 0 & 11 & 73,3 & 4 & 26,7 & 0 & 0 \\
\hline 2 & Kesling & 0 & 0 & 11 & 73,3 & 4 & 26,7 & 1 & 6,7 \\
\hline 3 & KB & 1 & 6,7 & 3 & 20 & 11 & 73,3 & 0 & 0 \\
\hline 4 & KIA & 0 & 0 & 6 & 40 & 9 & 60 & 0 & 0 \\
\hline 5 & Gizi & 0 & 0 & 2 & 13,3 & 13 & 86,7 & 0 & 0 \\
\hline 16 & Pengobatan & 0 & 0 & 6 & 40 & 9 & 60 & 0 & 0 \\
\hline & Jumlah & 1 & 1,1 & 38 & 42,2 & 50 & 55,6 & 1 & 1,1 \\
\hline
\end{tabular}

Sumber : Data primer

Menurut tabel 3.6 dapat dilihat bahwa sebagian besar job performance unit kerja Puskesmas di Kabupaten Gresik adalah cukup. Job performance terbaik terletak pada unit kerja gizi, sedangkan job performance terendah terletak pada unit kerja promosi kesehatan.

In role performance sebagai tingkat pencapaian pekerjaan yang ditugaskan. Hasil identifikasi in role performance unit kerja Puskesmas Di Kabupaten Gresik dapat dilihat pada tabel 3.7.

Tabel 3.7 Hasil Identifikasi In Role Performance Unit Kerja Puskesmas Di Kabupaten Gresik Tahun 2013

\begin{tabular}{|c|c|c|c|c|c|c|c|c|c|}
\hline \multirow[t]{3}{*}{ No } & \multirow[t]{3}{*}{ Unit Kerja } & \multicolumn{8}{|c|}{ Kategori In Role Performance } \\
\hline & & \multicolumn{2}{|c|}{$\begin{array}{l}\text { Sangat } \\
\text { Kurang }\end{array}$} & \multicolumn{2}{|c|}{ Kurang } & \multicolumn{2}{|c|}{ Cukup } & \multicolumn{2}{|c|}{ Baik } \\
\hline & & $\mathrm{n}$ & $\%$ & $\mathrm{n}$ & $\%$ & $\mathrm{n}$ & $\%$ & $\mathrm{n}$ & $\%$ \\
\hline 1 & Promkes & 3 & 20 & 6 & 40 & 2 & 13,3 & 4 & 26,7 \\
\hline 2 & Kesling & 7 & 46,7 & 0 & 0 & 4 & 26,7 & 4 & 26,7 \\
\hline 3 & KB & 1 & 6,7 & 0 & 0 & 1 & 6,7 & 13 & 86,7 \\
\hline
\end{tabular}




\begin{tabular}{|c|l|r|r|r|r|r|r|r|r|}
\hline \multirow{2}{*}{ No } & \multirow{2}{*}{ Unit Kerja } & \multicolumn{9}{|c|}{ Kategori In Role Performance } \\
\cline { 3 - 11 } & & \multicolumn{2}{|c|}{$\begin{array}{c}\text { Sangat } \\
\text { Kurang }\end{array}$} & \multicolumn{2}{|c|}{ Kurang } & \multicolumn{2}{c|}{ Cukup } & \multicolumn{4}{c|}{ Baik } \\
\cline { 3 - 11 } & & $\mathrm{n}$ & \multicolumn{1}{c|}{$\%$} & $\mathrm{n}$ & $\%$ & $\mathrm{n}$ & $\%$ & $\mathrm{n}$ & $\%$ \\
\hline 4 & KIA & 3 & 20 & 2 & 13,3 & 5 & 33,3 & 5 & 33,3 \\
\hline 5 & Gizi & 1 & 6,7 & 0 & 0 & 10 & 66,7 & 4 & 26,7 \\
\hline 6 & Pengobatan & 2 & 13,3 & 5 & 33,3 & 6 & 40 & 2 & 13,3 \\
\hline & Jumlah & $\mathbf{1 7}$ & $\mathbf{1 8 , 9}$ & $\mathbf{1 3}$ & $\mathbf{1 4 , 4}$ & $\mathbf{2 8}$ & $\mathbf{3 1 , 1}$ & $\mathbf{3 2}$ & $\mathbf{3 5 , 6}$ \\
\hline
\end{tabular}

Sumber : Data primer

Tabel 3.7 menunjukkan bahwa sebagian besar in role performance unit kerja Puskesmas di Kabupaten Gresik adalah baik. In role performance terbaik terletak pada program $\mathrm{KB}$, sedangkan in role performance terendah terletak pada unit kerja kesehatan lingkungan.

OCB merupakan perilaku pilihan yang tidak menjadi bagian dari kewajiban kerja formal seorang karyawan, namun mendukung berfungsinya organisasi tersebut secara efektif. Hasil identifikasi organizational citizenship behaviour unit kerja Puskesmas di Kabupaten Gresik dapat dilihat pada tabel 3.8.

Tabel 3.8 Hasil Identifikasi Organizational Citizenship Behaviour Unit Kerja Puskesmas di Kabupaten Gresik Tahun 2013

\begin{tabular}{|c|c|c|c|c|c|c|c|}
\hline \multirow[t]{3}{*}{ No } & \multirow[t]{3}{*}{ Unit kerja } & \multicolumn{6}{|c|}{ Kategori Organizational Citizenship Behaviour } \\
\hline & & \multicolumn{2}{|c|}{ Kurang } & \multicolumn{2}{|c|}{ Cukup } & \multicolumn{2}{|c|}{ Baik } \\
\hline & & $\mathrm{n}$ & $\%$ & $\mathrm{n}$ & $\%$ & $\mathrm{n}$ & $\%$ \\
\hline 1 & Promkes & 10 & 66,7 & 5 & 33,3 & 0 & ( \\
\hline 2 & Kesling & 10 & 66,7 & 4 & 26,7 & 1 & 6, \\
\hline 3 & KB & 6 & 40 & 9 & 60 & 0 & ( \\
\hline 4 & KIA & 5 & 33,3 & 10 & 66,7 & 0 & ( \\
\hline 5 & Gizi & 2 & 13,3 & 13 & 86,7 & 0 & ( \\
\hline 6 & Pengobatan & 7 & 46,7 & 8 & 53,3 & 0 & ( \\
\hline & Jumlah & 40 & $\mathbf{4 4 , 4}$ & 49 & 54,4 & 1 & 1, \\
\hline
\end{tabular}

Sumber : Data primer

Berdasarkan tabel 3.8 dapat dilihat bahwa rata-rata tingkat OCB unit kerja Puskesmas adalah cukup. Tingkat OCB terbaik terletak pada unit kerja gizi, sedangkan unit kerja dengan OCB terendah adalah promosi kesehatan.

Organizational

Citizenship

Behaviour dibentuk oleh lima dimensi yaitu altruism, conscientiousness, courtesy, civic virtue dan sportmanship. Setiap dimensi di dalam OCB memiliki peran yang berbeda-beda dalam membentuk OCB.

Hasil penelitian ini menunjukkan bahwa sebagian besar job performance unit kerja puskesmas di Kabupaten Gresik adalah cukup. Berdasarkan analisis deskriptif, in role performance unit kerja puskesmas di Kabupaten Gresik adalah baik. Hal ini disebabkan tugas yang harus dilakukan seperti pembuatan perencanaan dan pembuatan laporan sudah dilakukan dengan baik. Sehingga jumlah unit kerja puskesmas yang memiliki tingkat in role performance baik lebih banyak. Sedangkan rata-rata tingkat OCB unit kerja puskesmas adalah cukup. Subvariabel OCB terendah terletak pada dimensi conscientiousness.

Menurut Pantja Djati (2011) meningkatnya perilaku OCB dipengaruhi oleh dua faktor utama, yaitu faktor yang berasal dari dalam diri karyawan (internal) seperti moral, rasa puas, sikap positif, komitmen karyawan, serta motivasi sedangkan faktor yang berasal dari luar karyawan (eksternal) seperti sistem manajemen, sistem kepemimpinan, budaya organisasi. 
Job performance promosi kesehatan, kesehatan lingkungan, KIA dan pengobatan memiliki nilai paling rendah pada in role performance. Rendahnya in role performance unit kerja disebabkan oleh pertama, fungsi pengawasan yang belum berjalan efektif terutama masalah kehadiran.

Hal ini sejalan dengan penelitian Andini (2013) bahwa pengawasan berpengaruh signifikan terhadap kinerja pekerja.

Kedua, kurangnya apresiasi organisasi terhadap kinerja karyawan. Apresiasi organisasi terhadap karyawan yang berprestasi akan meningkatkan semangat kerja karyawan tersebut. Peningkatan semangat kerja tersebut secara otomatis akan membantu untuk meningkatkan produktivitasnya dalam bekerja.

Ketiga, kurangnya koordinasi antara unit kerja satu dengan yang lain. Menurut Asri (2013) koordinasi harus dilaksanakan dengan baik supaya dapat meningkatkan kinerja pegawai.

Keempat, masih tingginya sikap ego program. Jika ego program dapat diminimalkan maka tujuan organisasi dapat tercapai dengan cara efisiensi program. Menurut Isnandar (2012), efisiensi adalah elemen kunci dalam proses manajemen yang menyeimbangkan jumlah sumber daya yang digunakan dalam pencapaian tujuan.

Job performance $\mathrm{KB}$ dan gizi memiliki nilai paling rendah pada OCB. Rendahnya OCB unit kerja KB terletak pada dimensi conscientiousness atau perilaku sukarela. Sedangkan rendahnya OCB unit kerja gizi terletak pada dimensi courtesy. Seseorang yang memiliki dimensi courtesy atau menjaga hubungan baik dengan rekan kerja adalah orang yang menghargai dan memperhatikan orang lain.

Rendahnya OCB disebabkan oleh pertama, kurangnya jumlah tenaga kesehatan. Kedua, sikap egoisme terhadap program. Ketiga, kurangnya tingkat kepuasan kerja karyawan.

OCB lebih dipengaruhi oleh kepribadian atau lebih tepatnya kecerdasan emosi dibandingkan faktor-faktor situasional dan kondisi kerja di atas, atau OCB merupakan mediator atau perantara dari faktor tersebut.

Rendahnya in role performance KIA terletak pada kurangnya koordinasi antara unit kerja yang lain. Hal ini sejalan dengan penelitian Asri (2013) yang menyebutkan bahwa koordinasi memiliki hubungan yang positif terhadap kinerja.

Job performance gizi memiliki nilai terendah pada variabel OCB. OCB terendah terletak pada dimensi courtesy tepatnya pada kurangnya kesadaran bahwa pasien sudah menunggu lama dan pelayanan akan terganggu jika datang terlambat. Hal ini sejalan dengan penelitian Kepuasan kerja bukan mediator untuk meningkatkan OCB seseorang.

Rendahnya in role performance pada pengobatan disebabkan oleh tidak semua anggota unit kerja terlibat dalam pembuatan perencanaan dan kurangnya koordinasi antar unit kerja. Karyawan dalam keterlibatan yang tinggi dengan kuat memihak pada jenis kerja yang dilakukan dan benar-benar peduli dengan jenis kerja itu (Robbins, 2006).

Pada dasarnya semua pihak yang melakukan koordinasi dan hubungan kerja ia melakukan komunikasi. Dalam komunikasi harus memperhatikan elemenelemen dan jenis-jenis komunikasi agar koordinasi dan hubungan kerja efektif. Untuk mencapai keberhasilan koordinasi dan hubungan kerja semua pihak harus memperhatikan hambatan-hambatan komunikasi.

Upaya kesehatan pokok dapat dilihat pada hasil cakupan program pokok Puskesmas. Hasil identifikasi cakupan program pokok Puskesmas di Kabupaten Gresik dapat dilihat pada tabel 3.8. 
Tabel 3.8 Hasil Identifikasi Cakupan Program Pokok Puskesmas di Kabupaten Gresik Tahun 2013

\begin{tabular}{|c|c|c|c|c|c|c|c|}
\hline \multirow[t]{3}{*}{ No } & \multirow[t]{3}{*}{ Unit kerja } & \multicolumn{6}{|c|}{ Kategori Cakupan program pokok } \\
\hline & & \multicolumn{2}{|c|}{ Kurang } & \multicolumn{2}{|c|}{ Cukup } & \multicolumn{2}{|c|}{ Baik } \\
\hline & & $\mathrm{n}$ & $\%$ & $\mathrm{n}$ & $\%$ & $\mathrm{n}$ & $\%$ \\
\hline 1 & Promkes & 11 & 73,3 & 2 & 13,3 & 2 & 13,3 \\
\hline 2 & Kesling & 2 & 13,3 & 11 & 73,3 & 2 & 13,3 \\
\hline 3 & KB & 0 & 0 & 1 & 6,7 & 14 & 93,3 \\
\hline 4 & KIA & 5 & 33,3 & 4 & 26,7 & 6 & 40 \\
\hline 5 & Gizi & 2 & 13,3 & 7 & 46,7 & 6 & 40 \\
\hline 6 & Pengobatan & 3 & 20 & 4 & 26,7 & 8 & 53,3 \\
\hline & Jumlah & 23 & 25,6 & 29 & 32,2 & 38 & 42,2 \\
\hline
\end{tabular}

Sumber : Data Sekunder Hasil Penilaian Kinerja Puskesmas Tahun 2012

Berdasarkan tabel 3.8 dapat diketahui bahwa sebagian besar cakupan program pokok Puskesmas di Kabupaten Gresik adalah baik. Cakupan program pokok tertinggi terletak pada unit kerja $\mathrm{KB}$, sedangkan cakupan program pokok terendah terletak pada unit kerja promosi kesehatan.

Promosi kesehatan memiliki cakupan unit kerja paling rendah di antara unit kerja yang lain. Hal ini disebabkan oleh kurangnya tingkat efektivitas tim dan in role performance unit kerja promkes.

Unit kerja kesehatan lingkungan memiliki tingkat OCB paling rendah di antara unit kerja lain. KB, KIA, Gizi dan Pengobatan memiliki kategori cakupan unit kerja baik.

Berdasarkan Depkes RI (2009) menyebutkan bahwa puskesmas merupakan pusat penggerak pembangunan berwawasan kesehatan. Akan tetapi hal tersebut sangat ironis dengan hasil cakupan unit kerja promosi kesehatan dan lingkungan serta hasil identifikasi work attitude.

Berdasarkan uji regresi linier sederhana menunjukkan bahwa organizational commitment unit kerja dipengaruhi oleh job satisfaction (p: <0,001) unit kerja Puskesmas. Job involvement unit kerja dipengaruhi oleh job satisfaction (p: $<0,001)$ dan organizational commitment (p: <0,001) unit kerja Puskesmas. Job performance unit kerja dipengaruhi oleh work attitude (p: <0,001) unit kerja. Job performance dipengaruhi job satisfaction (p: 0,001), job involvement ( $\mathrm{p}:<0,001)$ dan organizational commitment (p: $<0,001)$.

In role performance dipengaruhi oleh job satisfaction (p: 0,001), job involvement (p: 0,001) dan organizational commitment (p: <0,001).

OCB dipengaruhi oleh job satisfaction (p: 0,008), job involvement (p: 0,005) dan organizational commitment ( $\mathrm{p}:<0,001)$.

Cakupan program pokok Puskesmas dipengaruhi oleh job satisfaction (p:0,002; B: 0,661), organizational commitment (p: $<0,001 ; B: 1,893)$, in role performance (p:0,002; B: 1,371) dan organizational citizenship behaviour (p:0,021; B: 0,563).

Pada dasarnya melaksanakan komitmen sama saja maknanya dengan menjalankan kewajiban, tanggung jawab, dan janji yang membatasi kebebasan seseorang untuk melakukan sesuatu. Semakin tinggi derajat komitmen karyawan semakin tinggi pula kinerja yang dicapainya dan semakin efektif suatu perusahaan dalam mencapai tujuannya. (Yudhaningsih, 2011).

Pada penelitian ini cakupan unit kerja dipengaruhi oleh job involvement, job satisfaction, organizational commitment dan in role performance. Karyawan yang memiliki keterlibatan kerja tinggi maka memiliki kepedulian 
yang tinggi terhadap pekerjaan dan organisasi, merasa puas dengan pekerjaannya, memiliki komitmen yang tinggi terhadap profesi, karir, dan organisasi serta memberi usaha yang terbaik untuk organisasi.

Luthans (2006) mengemukakan bahwa kepuasan kerja berpengaruh terhadap, pertama yaitu kinerja. Karyawan yang tingkat kepuasannya tinggi, kinerja akan meningkat, walaupun hasilnya tidak langsung. Ada beberapa variabel moderating yang menghubungkan antara kinerja dengan kepuasan kerja, terutama penghargaan.

Kedua, pergantian karyawan. Kepuasan kerja yang tinggi tidak akan membuat pergantian karyawan menjadi rendah, sebaliknya bila terdapat ketidakpuasan kerja, maka pergantian karyawan mungkin akan tinggi.

Selain itu, Robbins (2006) mengungkapkan dampak kepuasan kerja jika dipenuhi dapat meningkatkan produktifitas, menurunkan abesentisme, menekan perputaran kerja. Menurut Borman, W. C. \& Motowidlo, S.J. (2003) in role performance yang dikenal sebagai task performance menunjukkan kriteria pada aspek teknikal pekerjaan karyawan.

Isu strategis berdasarkan hasil penelitian deskriptif, yaitu:

a. Rendahnya job involvement unit kerja Puskesmas

b. Rendahnya job satisfaction unit kerja Puskesmas

c. Rendahnya in role performance unit kerja Puskesmas

d. Rendahnya organizational citizenship behaviour unit kerja

Berdasarkan hasil analisis statistik, yaitu rendahnya jumlah unit kerja yang memiliki cakupan program pokok dengan kategori baik sebesar 42,2\% $(<80 \%)$ pada tahun 2012, cakupan program pokok Puskesmas dipengaruhi oleh job satisfaction, organizational commitment, job involvement, in role performance.

Berdasarkan hasil penelitian dapat diketahui bahwa work attitude dan job performance beberapa unit kerja termasuk dalam isu stategis yang harus diselesaikan untuk meningkatkan cakupan program pokok puskesmas dan perlu peningkatan bagi unit kerja yang sudah memiliki work attitude dan job performance dengan kategori baik.

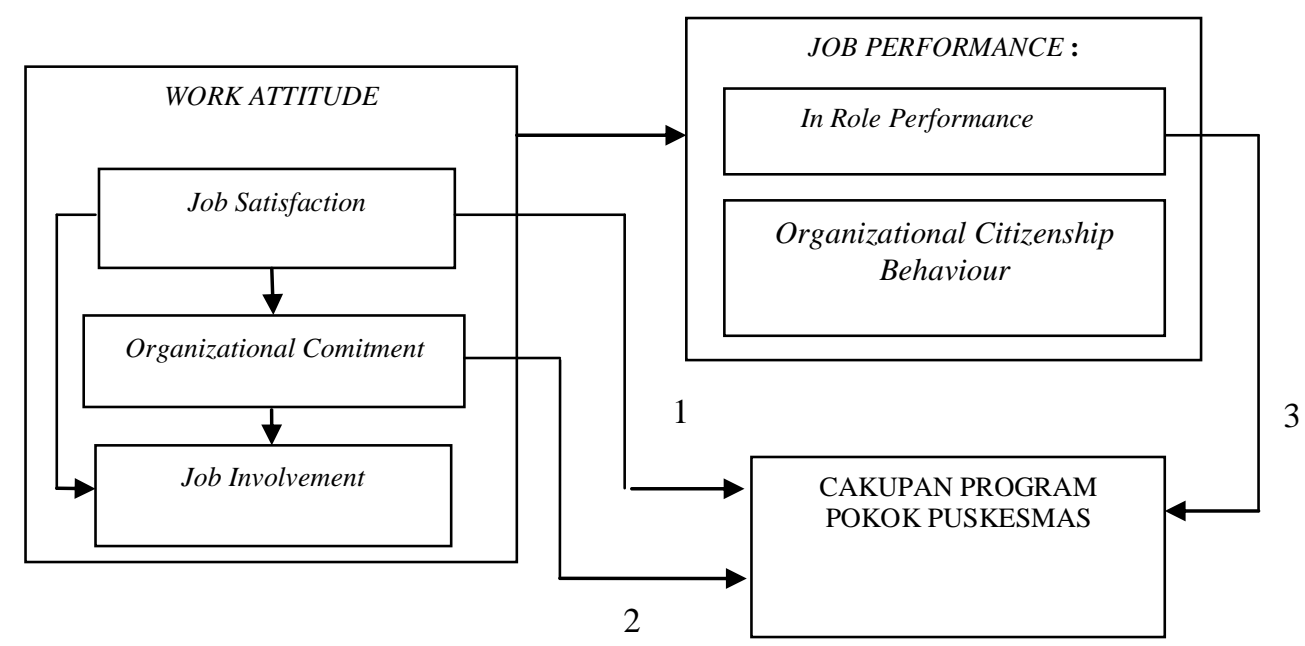

Gambar 3.1 Rekomendasi Berdasarkan Hasil Uji Regresi Linier

Keterangan :

1 : Job satisfaction merupakan prioritas pertama untuk meningkatkan cakupan program Pokok Puskesmas
2 : Organizational

commitment merupakan prioritas kedua untuk meningkatkan cakupan program Pokok Puskesmas 
3 :In role performance merupakan prioritas ketiga untuk meningkatkan cakupan program Pokok Puskesmas

\section{SIMPULAN}

Berdasarkan hasil penelitian, analisis hasil penelitian dan FGD dalam pembahasan dapat diambil kesimpulan sebagai berikut :

1. Rata-rata kategori work attitude unit kerja Puskesmas di Kabupaten Gresik adalah cukup.

2. Tingkat kepuasan kerja unit kerja Puskesmas terbanyak adalah cukup.

3. Sebagian besar komitmen tim unit kerja Puskesmas adalah baik.

4. Sebagian besar job involvement unit kerja program pokok Puskesmas di Kabupaten Gresik adalah cukup

5. Sebagian besar job performance unit kerja Puskesmas di Kabupaten Gresik adalah cukup.

6. Rata-rata tingkat OCB unit kerja Puskesmas adalah cukup.

7. Sebagian besar cakupan program pokok Puskesmas di Kabupaten Gresik adalah baik.

8. Cakupan program pokok Puskesmas dipengaruhi oleh in role performance, job involvement, job satisfaction dan organizational commitment

9. Rekomendasi untuk meningkatkan cakupan program pokok Puskesmas di Kabupaten Gresik Tahun 2013 adalah sebagai berikut :

a. Meningkatkan job satisfaction dapat dilakukan melalui:

1. Memberikan pujian kepada unit kerja yang berhasil mencapai target melalui microphone setiap pagi pada jam kerja untuk memotivasi unit kerja lain

2. Menempatkan foto anggota unit kerja yang paling berprestasi di area Puskesmas

3. Membuat lomba antar unit kerja yang berprestasi

4. Kerja sama dengan industri dapat terjalin melalui industri yang terlibat dengan kegiatan
CSR (Corporate Social Responsibility)

5. Pengadaan rotasi jabatan koordinator program setiap 3 tahun sekali dalam satu puskesmas dan antar puskesmas

b. Meningkatkan organizational commitment melalui peningkatan job satisfaction

c. Job involvement, yaitu dengan cara:

1. Meningkatkan job satisfaction

2. Mengadakan breafing dan doa bersama untuk seluruh anggota unit kerja gizi setiap pagi.

3. Menyampaikan hasil pelatihan pada forum pertemuan di Puskesmas

4. Memberikan reward bagi karyawan yang berprestasi

5. Melakukan pendekatan untuk mengoptimalkan kinerja karyawan

d. Meningkatkan in role performance dengan cara meningkatan organizational commitment melalui peningkatan job satisfaction

\section{BAHAN RUJUKAN}

Andini, SWD 2013 Pengaruh pengawasan dan motivasi terhadap kinerja Pekerja bagian taman dinas kebersihan dan pertamanan Kota samarinda, Samarinda, sitasi tanggal 21 Juli 2013, http://www.journal.feunmul.in/ojs/in dex.php/publikasi.../47

Asri, Yola Yulinda, 2013. Pengaruh Koordinasi Terhadap Kinerja Pegawai Dinas Koperasi Usaha Mikro Kecil Menengah Perindustrian Dan Perdagangan Kota Tasikmalaya. Journal Universitas Siliwangi

Tasikmalaya.http://journal.unsil.ac.id /jurnalunsil-1951-.html (diakses 7 juli 2013) 
Borman, W. C. \& Motowidlo, S.J., 2003. Expanding The Criterion Domain to Include Elements of Extra-role Performance, dalam Schmitt, N. \& Borman, W. C. (editors). Personnel Selection in Organizations. San Francisco: Jossey-Bass.

Djati, Pantja S 2011, Variabel Anteseden Organizational Citizenship Behavior (OCB) Dan Pengaruhnya Terhadap Service Quality Pada Perguruan Tinggi Swasta Di Surabaya 2011, Surabaya, Sitasi 8 October 2012, http://fportfolio.petra.ac.id/user_files 191-023/OCB-

SERVICE\%20JOURNAL-

S.Pantja.Djati.doc

Depkes RI 2009, Kebijakan Dasar Puskesmas (Kepmenkes No 128 tahun 2004), Jakarta.

Emilisa, Netania 2001, Hubungan Antara Job Satisfaction Dengan Organizational Commitment Pada Dana Pensiun Lembaga Keuangan Yang Dikelola Oleh Perusahaan Asuransi di Jakarta, Jurnal Media Riset Bisnis \& Manajemen, Volume 1 No.3, pp. $229-244$.
Isnandar, Yudi, 2012. Manajemen Organisasi. http://yudiisnandar.blogspot.com/2012/09/man ajemen-organisasi.html (diakses 21 Juli 2013)

Luthans, Fred 2006, Perilaku Organisasi $10^{\text {th }}$, Edisi Indonesia, Yogyakarta, Penerbit ANDI.

Robbins, P. Stephen, 1996. Perilaku Organisasi. Jakarta: PT Prinhalindo.

Robbins, P Stephen 2006, Perilaku Organisasi, Salemba Empat, Jakarta.

Robbins, SP \& Judge, TA 2008, Perilaku Organisasi Buku 1 : Organizational behaviour, twelevth edition, Salemba empat, Jakarta.

Yudhaningsih, Resi 2011, Peningkatan Efektivitas Kerja Melalui Komitmen, Perubahan dan Budaya Organisasi, Jurnal Pengembangan Humaniora, Vol. 11 No. 1, April 2011 